\title{
Um olhar sobre o impacto da experiência teatral no exercício da alteridade e no processo de socialização de crianças em contextos educacionais
}

\section{A look at the impact of theater experience in the exercise of alterity and in the child socialization process in educational contexts}

\section{DOI: http://dx.doi.org/10.5965/198431781642020143}

\author{
Celida Salume Mendonça \\ Universidade Federal da Bahia - UFBA \\ celidasm@gmail.com | ORCID | LATTES \\ Isabel Bezelga \\ Universidade de Évora - UEVORA \\ isabelmbezelga@gmail.com | ORCID | Ciência Vitae ID
}

\begin{abstract}
RESUMO
As reflexões que aqui seguem dialogam com a investigação de pós-doutoramento realizada no Centro de História da Arte e Investigação Artística da Universidade de Évora (CHAIA), que buscou aprofundar a ideia de que o uso intencional de diferentes materialidades nos percursos de criação teatral mobiliza os envolvidos, ajudando-os a reagir às experiências instauradas e facilitando a interação entre os participantes. O artigo divide-se em duas partes centrais: a primeira contém a explanação de um recorte da experiência de ensino vivenciada com os alunos do curso Licenciatura Educação Básica da Universidade de Évora, na disciplina Oficina de Integração das Expressões; e a segunda é dedicada a questões suscitadas pelo fazer teatral desenvolvido com crianças no contexto de educação básica $1^{\circ}$ ciclo na Escola da Cruz da Picada. As múltiplas possibilidades oferecidas pelas materialidades em jogo nos dois contextos, abrem perspectivas aos participantes pensando e fazendo, para serem inventivos e sensíveis. Como o processo de aprendizagem passa pelo seu corpo e o corpo do outro, permite vivenciar novas formas de comunidade, concebendo de modo mais amplo a alteridade. Os resultados obtidos voltam-se para o aperfeiçoamento da formação de docentes e pesquisadores da pedagogia do teatro no contexto brasileiro e português construindo novas colaborações.
\end{abstract}

Palavras-chave: Experiência teatral; Corpo; Materialidades; Alteridade; Contexto educacional.;

\section{ABSTRACT}

The reflections that follow here dialogue with the post-doctoral research carried out at the Center for the History of Art and Artistic Research (CHAIA), which sought to deepen the idea that the intentional use of different materialities in the paths of theatrical creation mobilizes those involved helping to react to the established experiences, facilitating the interaction between the participants. The article is divided into two central parts: the first contains a presentation of an excerpt of the teaching experience lived with the students of the Basic Education Degree course at the University of Évora, in the discipline Workshop on 
Integration of Expressions; and the second is dedicated to issues raised by the theatrical work developed with children, in the context of basic education 1st cycle at Escola da Cruz da Picada. The multiple possibilities offered by the materialities at play in the two contexts, open perspectives to participants thinking and doing, to be more inventive and sensitive. As the learning process passes through your body and the other's body, it allows you to experience new forms of community, conceiving alterity in a broader way. The results obtained are aimed at improving the training of teachers and researchers in theater pedagogy in the Brazilian and Portuguese context, building new collaborations.

Keywords: Theatrical experience; Body; Materialities; Alterity; Educational context;

Se Ihe chamo "princípio de transformação" é porque esse sujeito sensível, vulnerável e ex/posto é um sujeito aberto a sua própria transformação. Ou a transformação de suas palavras, de suas ideias, de seus sentimentos, de suas representações, etc. De fato, na experiência, o sujeito faz a experiência de algo, mas, sobretudo, faz a experiência de sua própria transformação. Daí que a experiência me forma e me transforma.

Jorge Larrosa

\section{1. "PRA COMEÇO DE CONVERSA"}

Neste artigo problematizamos ações, experiências e iniciativas que dialogam com a investigação de pós-doutoramento realizada no Centro de História da Arte e Investigação Artística (CHAIA) a partir do projeto Materialidade afetiva em jogo: processos de experimentação, aprendizagem e criação teatral na escola. A pesquisa vem aprofundando a ideia de que o uso intencional de diferentes materialidades nas aulas de Expressão Dramática e nos percursos de criação teatral mobiliza os envolvidos ajudando-os a reagir às experiências instauradas, favorecendo 0 processo de socialização e, assim, minimizando as situações de exclusão vivenciadas por muitas crianças, no contexto educacional.

As múltiplas possibilidades oferecidas pelas materialidades em jogo abrem perspectivas para o pensar, o imaginar e o fazer, tornando os alunos/participantes mais inventivos e sensíveis. Além disso, viabilizam um processo de aprendizagem que passe necessariamente pelo nosso corpo e o do outro, permitindo experienciar novas formas de comunidade e concebendo de modo mais amplo a noção de alteridade e o processo de socialização. A constituição do comum nas aulas de 
Expressão Dramática (Portugal) e de Arte/Teatro (Brasil) pode gerar novos modos de existência, de criar juntos e de transformação.

São chamadas aqui de "materialidades",objetos, tecidos, imagens, músicas, substâncias, elementos da natureza (água, areia, folhas, aromas) - ou até mesmo o próprio espaço enquadrado - introduzidos intencionalmente como desencadeadores de exercícios, propostas, jogos ou mesmo para a construção de personagens, narrativas e/ou cenas. Em seu texto Sobre importâncias: saboreando materialidades no processo de criação cênica, a coautora Celida Salume defende que o princípio da multiplicidade está na infinidade de combinações possíveis quando colocamos esses elementos em contato com a heterogeneidade dos estudantes e suas subjetividades. O corpo, como principal materialidade do fazer teatral converte-se na própria fonte de invenção criativa. Instaurar um jogo ou improvisação partindo de um elemento concreto motiva e inspira o grupo envolvido na experiência, contribuindo para a entrada destes em uma nova atmosfera. Como Cecília Salles bem referiu: "qualquer coisa pode ser esse corpo que excita a imaginação" (1998, p.57).

A metodologia centra-se num plano de ação-investigação empírico voltado para um conjunto de procedimentos, análise de experiências e iniciativas das duas pesquisadoras, bem como produções anteriores que friccionam com as atuais inquietações. Como investigadora, a coautora Celida Salume realizou recolha de dados e posterior análise através dos registros escritos e imagéticos apresentados pelos alunos do processo das aulas. Estes foram complementados com reflexões acerca do seu contato direto com o ambiente de recolha dos dados e diálogo constante com a supervisora do projeto Isabel Bezelga, também coautora do artigo.

As ações desenvolvidas contaram com a participação da professora Celida Salume como docente convidada em dois diferentes contextos. O primeiro se refere a sua colaboração na Oficina de Integração das Expressões do Departamento de Pedagogia e Educação da Universidade de Évora em 2019, direcionada para futuros professores e professoras. O segundo, diz respeito à sua participação, no mesmo ano, como professora de Expressão Dramática juntamente com o professor e artista Diogo Duro na Escola Básica da Cruz da Picada através do Projeto MUS-E 
promovido pela Associação Menuhin Portugal, na qual a Prof ${ }^{a}$ Isabel Bezelga integra a direção. O projeto MUS-E (desde 2000), Musas Europa - Artistas na Escola, foi criado por Yehudi Menuhin, violinista e compositor, militante dos direitos humanos, grande defensor da tolerância e da cooperação entre povos e culturas. As atividades do projeto decorrem em horário escolar objetivando a inserção das atividades de Expressão Artística, no currículo de escolas do $1^{\circ}$ ciclo. Ele apoia-se em dois pressupostos fundamentais: a educação para a diversidade e a prevenção da violência, através das artes. Outro motivo que justifica a escolha da escola portuguesa como um dos campos de investigação é a proximidade com a população escolar socialmente desfavorecida, que encontramos também na realidade brasileira, o que inclui crianças com problemas de aprendizagem e socialização.

No processo teatral desenvolvido e realizado em contextos educacionais, a alteridade é identificada como forma de visibilidade, de escuta e de relação dos participantes entre si. A questão da alteridade constitui-se como condição mínima necessária ao desenvolvimento da prática criativa teatral de caráter coletivo. Colocar o outro no lugar do ser, e não simplesmente como um objeto para um sujeito, era uma das ideias defendidas pelo filósofo franco-lituano Emmanuel Lévinas (2005). Em vez do indivíduo agir frente ao outro como gostaria de ser tratado, é a descoberta do outro que impõe a sua conduta.

Muitas instituições educacionais buscam prioritariamente a ordem, a disciplina e a homogeneidade, sem a influência do outro, no intuito de igualar os estudantes o que não propicia uma relação diferenciada com o próprio espaço e com os demais. No fazer teatral Jean-Pierre Ryngaert (2009) aborda o jogo como um lugar de encontros e trocas, no qual cada jogador joga para si, para os outros e, igualmente, diante dos outros. A alteridade é o que dá movimento ao processo, e é nessa experiência que reside a possibilidade de se colocar no lugar do outro, de exercitar a empatia, de escutar e reagir ao que é proposto sendo receptivo. Nas aulas de teatro, ao conseguirmos nos demarcar em termos de alteridade estamos sendo afetados e implicados com pessoas e coisas que viabilizam nosso projeto e desejo de ser, nosso movimento concreto no mundo. O que torna o ato criador sempre político, em 
seu caráter transformador. Esse caminho é uma construção constante na prática colaborativa entre os estudantes, entre professores e estudantes, entre investigadores e artistas, para juntos inventarmos novos mundos possíveis.

\section{O TEATRO EM CONTEXTO EDUCACIONAL: ENCONTROS ENTRE BRASIL E PORTUGAL}

Em Portugal, o ensino de Teatro não é considerado obrigatório na educação básica, podendo ser oferecido como opção nos $2^{\circ}$ e $3^{\circ}$ ciclos. Embora a área de Expressão Dramática e movimento esteja consignada nas Orientações Curriculares quer para a Educação Pré-escolar, quer para $01^{\circ} \mathrm{Ciclo,}$ ela é da responsabilidade dos professores titulares de turma (monodocentes) e principalmente desenvolvida pelos profissionais da Educação Infantil. A presença do Teatro nas escolas públicas ocorre de forma muito tímida através da oferta de oficinas ou nos Programas de Enriquecimento Curricular (AEC) com outros profissionais. A Lei de Bases do Sistema Educativo Português (Lei n. 46/86, de 14 de outubro) articula plenamente a necessidade da educação artística como componente essencial da educação global da criança, entretanto, o sistema de ensino oficial privilegia apenas as artes visuais como obrigatórias e a música até ao final do $2^{\circ}$ Ciclo.

Enquanto responsável também pela formação de educadores e professores generalistas na Universidade de Évora, a coautora Isabel Bezelga sinaliza no artigo O Papel das Artes na Promoção do Sucesso Académico: O Prazer de Fazer Acontecer! (2017), que é cada vez mais reduzido o tempo consignado às Unidades curriculares de educação e expressão artística durante a sua formação, o que, resulta em uma vivência cultural e artística mais frágil, comprometendo a familiaridade, a experiência, o conhecimento e a vontade de explorar os territórios da criação artística.

Existe a necessidade de revitalizar as práticas de educação artística em contexto escolar com o contributo de boas experiências que, através do desenvolvimento de processos participativos, possibilitem o envolvimento nesses 
percursos criativos, o reconhecimento das suas múltiplas linguagens por crianças, jovens e comunidades, alcançando objetivos significativos. As mudanças e transformações podem acontecer quando criamos motivação e entusiasmo pela escola, implicando as famílias e a comunidade, promovendo a relação entre pares. Essas são seguramente condições essenciais para a autoestima dos alunos, dos professores e de toda a comunidade educativa.

Participando da formação desses educadores ao assumir parte das aulas da disciplina Oficina de Integração das Expressões (2019.1), a coautora Celida Salume provocou os estudantes da Universidade de Évora a olharem criticamente para suas vivências. Indagados sobre Qual a crítica que fazemos à escola que está dentro de nós próprios? eles responderam em sua grande maioria que: *Deveriam existir nas escolas mais aulas de expressão corporal, de música, de dança, de teatro, e mais professores que dinamizem atividades expressivas; *Falta tempo para atividades em conjunto onde as crianças possam se unir, se divertir e conviver aprendendo; * $A$ aprendizagem feita na escola devia ser através de algo mais prático e um pouco menos teórico; *Falta de diferenciação, de oportunidades individualizadas, de diversidade de estratégias - fazer coisas diferentes para cada aluno, pois nem todos são iguais; *Falta mais alegria, liberdade, falta a possibilidade de se aprender com estratégias mais dinâmicas; *Falta de estímulo a imaginação, a criação, ao "pensar fora da caixa", diferente.

As discussões geradas foram alimentadas inicialmente pela reverberação de sensações de leveza, fluidez, felicidade, liberdade, imaginação, e principalmente, de interação, ocasionadas pela exploração de tecidos e lenços em movimento em um jogo improvisacional realizado em uma das aulas pelos estudantes da Universidade de Évora.

Quanto aos objetivos, tais vivências não se restringem apenas a sensibilização dos estudantes, mas principalmente a preparação dos futuros educadores. Ao passarem pela experiência de incluírem intencionalmente diferentes materialidades em exercícios e jogos improvisacionais, foi possível verificar como esses elementos aproximam os participantes e podem ajudar no processo de 
inclusão no contexto educacional. Os educadores exercem um papel singular nesse processo através do caráter lúdico das experiências que instauram dentro e fora da sala de aula e de sua mediação pontual com crianças, que nem sempre se sentem integradas ao grupo.

Figura 1: Oficina de Integração das Expressões - Colégio dos Leões - Universidade de Évora

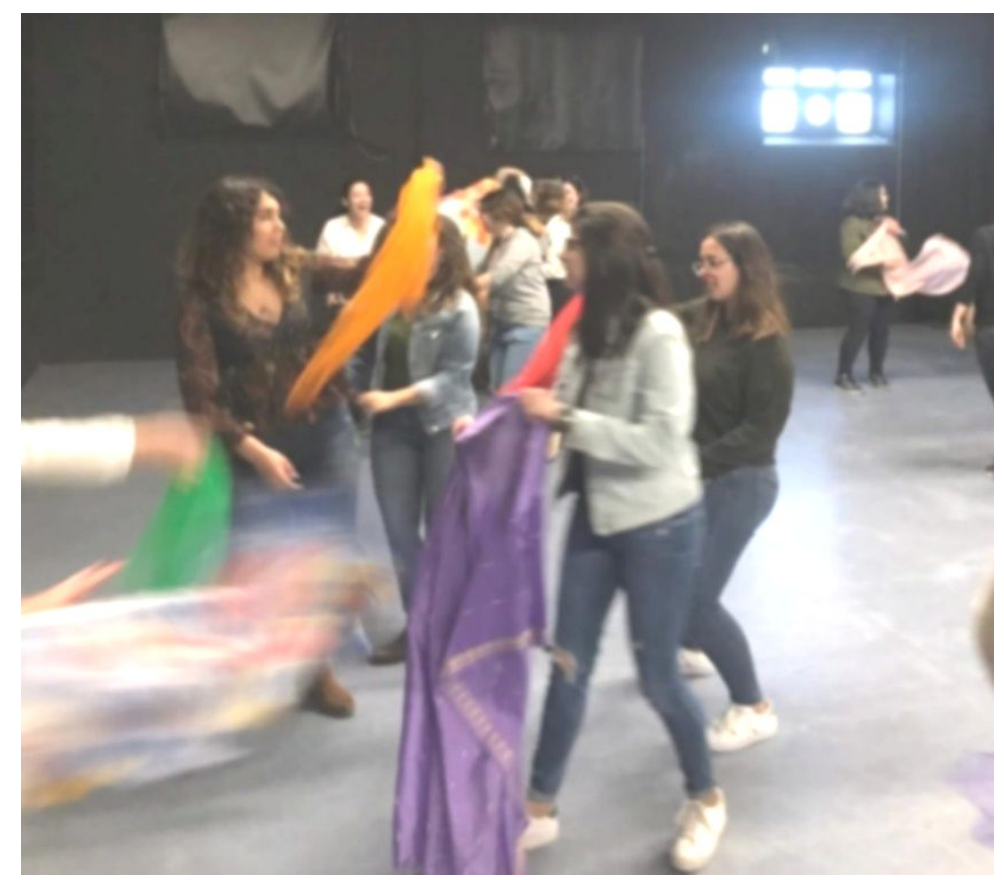

Fonte: Arquivo pessoal - março 2019

As múltiplas possibilidades oferecidas pelas materialidades em jogo, ajudava-os a reagir às experiências instauradas. Cecília Salles (2008) ao refletir sobre os modos de desenvolvimento do nosso pensamento e de nossas lembranças - uma das matérias primas da criação - afirma que nossas sensações não são isoladas, uma imagem evoca a outra, nossa: "memória é continuidade, que se dá no campo das interações" (p.67). Nesse sentido, é importante salientar que o processo de criação está localizado no campo relacional. Assim, todos esses estímulos passam a alimentar futuros processos inventivos. Os percursos criativos desenvolvidos em sala de aula são processos em transformação que envolvem uma diversidade de mediações. Enquanto estudantes em formação, futuros pedagogos, 
que irão trabalhar com as expressões artísticas em sala de aula, torna-se fundamental reconhecer essas experiências, também como espaço de constituição de sua subjetividade.

Questionados sobre suas impressões e recepção em relação ao jogo e ao trabalho criativo com imagens, os estudantes registraram que "são importantes para repensarmos nossas ações e dão um sopro de renovação e inspiração para a prática”. Em Jogar, representar (2009), Jean-Pierre Ryngaert fala da importância de sustentar o prazer do formador, que nasce também da experimentação de novos elementos, e é tão importante para a qualidade do trabalho. Outro aluno de mobilidade ${ }^{1}$ afirmou que "me he sentido como un niño, recordando el momento al representar imágenes (felicidad, energía)"2 (J.M.) O que reflete o engajamento pessoal como motor indispensável ao jogo.

Para Ryngaert (2009, p. 34), o jogo "nos interessa ao mesmo tempo como experiência sensível, experiência artística e relação com o mundo". Os jogos incluíam em uma de suas variações a possibilidade de mostrar com o corpo o que viam nas imagens, sem contar, mas fisicalizando. As sensações de liberdade, energia, entusiasmo, criatividade e divertimento estavam presentes em seus registros. Essas sensações por estarem relacionadas com as materialidades trabalhadas são amplificadas, facilitando que certas percepções fiquem na memória. Memória e percepção são revestidas de afetividade e têm a emoção como elemento comum, são móveis e reconstruídas continuamente a partir de nossas ações. Ryngaert sinaliza ainda que "estar no jogo desencadeia uma disponibilidade sensorial e motora, libera um potencial de experimentação" (2009, p.56).

Além do foco no processo criativo dramático, as práticas desenvolvidas com os futuros educadores incluíam atividades que necessariamente os colocava em relação com os outros. Em um dos encontros eles escreviam em pequenos papéis imagens que reverberavam da aula anterior e inseriam-nos dentro de balões, que

\footnotetext{
${ }^{1} \mathrm{O}$ programa de Mobilidade de estudantes permite que alunos desenvolvam um período de estudos noutra instituição com a qual exista Acordo/Protocolo, que poderá ir de um semestre até um período máximo de 12 meses.

2 "me senti como criança, recordando o momento em que representava imagens (felicidade, energia)" J.M. (Tradução nossa)
} 
em sequência inflavam para brincar. Com os balões já cheios, a indicação era explorar movimentos em duplas, depois em conjunto, e por último, se deslocar pelo espaço com o balão conectando uma parte do seu corpo com a do colega. Por último, em duplas, com um forte abraço estourar um dos balões e verificar qual imagem ele continha. Reunidos em grupos criavam imagens coletivas, quadros vivos que poderiam ainda se desdobrar em improvisações.

Em reflexões realizadas ao final dos encontros, os participantes da disciplina concluíram que a instituição escolar caminha cada vez mais para um ensino "conteudista". E que a escola que muitos deles vivenciaram, da mesma forma que a que encontram atualmente, é extremamente controladora, reguladora, preocupada prioritariamente com a disciplina e com uma cobrança muito alta da aprendizagem quantitativa de conteúdos. Consideraram em suas falas e registros que a escola necessitaria de mais aulas de expressão artística nos seus diferentes níveis de ensino, o que permitiria às crianças e jovens trabalharem os seus sentimentos, o seu corpo expressivamente e as relações entre si. A escola poderia ainda ser menos padronizada, permitindo que os educandos se expressassem individualmente e em grupo, abrindo um espaço de escuta, o que contribuiria certamente para o interesse desses pelas aulas, beneficiando professores e estudantes.

Em Elogio da Escola, Jorge Larrosa (2017) pontua que a crítica a escola se tornou um lugar comum e nos convida a repensá-la amorosamente e exprimirmos nossa voz como pedagogos, não apenas como professores. Nos provoca a pensarmos a escola como um lugar de sentir curiosidade e interesse, um sentir provocado pela experiência. Um lugar para se ter tempo, para errar, para recomeçar, para criar. Uma escola em que se permita estar ao ar livre. Uma escola que reconheça o corpo enquanto materialidade escolar: o "corpo como artefacto que age sobre algo, mas também corpo sobre o qual se age". (idem, p.264)

A escola perfeita para P.L., aluno do programa de mobilidade acadêmica, que frequentou a disciplina Oficina de Integração das Expressões: "sería aquella que fuesse capaz de transmitir unos conocimientos y unos valores de una manera entretenida, preocupándose por la diversidad del alumnado" (P.L.) $)^{3}$; outros ainda 
destacaram: "una escuela que disfrutes aprendiendo, mejorando más la parte social" (J.M. $)^{4}$; "menos tempo com os livros, aprender com coisas mais dinâmicas" (M.S.); "diferenciação pedagógica, existir alternativas para os alunos, pois nem todos são iguais" (S.G.). Para eles é rara nas escolas a presença de professores que dinamizem atividades mais expressivas.

Em seu artigo Revisitar os percursos da educação artística para enfrentar desafios: o caso do teatro-educação (2015), a coautora Isabel Bezelga recupera e enfatiza a importância das atividades lúdicas e da experiência artística no contexto educacional:

Os contributos de Dewey $(1958,1971)$ e Read (1982) realçaram a importância que a arte pode desempenhar no processo educativo. Encarnaram a perspectiva que sublinha a importância da experiência, percepcionando-a como mais válida do que a teorização e a própria instrução formal. Para ambos os autores, a afectividade e a experiência pessoal e directa da criança e do jovem desempenham um papel insubstituível no seu processo de educação. (idem, p.22)

Muitas pesquisas nas áreas da Educação e das Artes defendem que a realização de atividades lúdicas e expressivas e a mediação adequada de um adulto, originam ganhos no desenvolvimento das crianças envolvidas, principalmente nos aspectos de socialização. Infelizmente, a partir do ensino básico desconsidera-se essa premissa mantendo os alunos em atividades enfadonhas, pouco atrativas, praticamente imóveis nas carteiras escolares e submetidos a uma pedagogia diretiva com aulas expositivas. As impressões descritas pelos estudantes da Universidade de Évora em relação a importância de um trabalho que inclua o corpo expressivamente e o jogo, nem sempre são sustentadas na prática quando encontramos os professores nas escolas mais preocupados com o controle da turma e com o cumprimento de um extenso currículo.

Neste contexto, as pesquisadoras observam que, apesar de haver em Portugal e no Brasil uma abertura para novas metodologias com objetivos pedagógicos que contemplem aspectos lúdicos e expressivos, bem como o registro

\footnotetext{
3 "seria aquela que fosse capaz de transmitir conhecimentos e valores de uma forma divertida, preocupando-se com a diversidade do alunado" (P.L.) (Tradução nossa)

4 "uma escola da qual usufruas aprendendo, melhorando a parte social" (J.M.) (Tradução nossa)
} 
de projetos de destaque; na prática, as instituições escolares minimizam a sua importância, e seguem preocupados com a demanda de conteúdos e metas a serem alcançadas.

\subsection{Questões suscitadas pelo fazer teatral na Escola da Cruz da Picada e no Encontro internacional de artistas e docentes do Projeto MUS-E}

Na Escola Básica da Cruz da Picada em Évora (PT), como em outras escolas brasileiras, muitas crianças sofrem situações de abandono e de maus tratos, vivem em ambientes desfavorecidos e as próprias famílias não consideram como importantes, espaços para brincar e se relacionar. Encontramos também nessas escolas crianças que apresentam dificuldades em diferentes aspectos. São crianças portuguesas, brasileiras, de origem africana, ou de etnia cigana. Crianças de famílias emigradas, crianças em condições típicas de aprendizagem, crianças com muitas dificuldades de aprendizagem e de relação, crianças diagnosticadas com autismo e outras ainda, sem diagnóstico preciso.

Alguns destes alunos com diagnóstico de autismo, que frequentam o $1^{\circ}$ Ciclo na Escola da Cruz da Picada vêm participar das aulas de Expressão Dramática esporadicamente, mas não são bem recebidos pelos colegas, pois não há uma frequência deles nesses encontros e no acompanhamento de todas as atividades do grupo de forma articulada. Na ocasião em que a investigadora, coautora do texto Celida Salume começou a acompanhar as turmas conduzidas pelo professor/artista Diogo Duro, os estudantes já se encontravam em processo de montagem e registro imagético do percurso criativo, que seria posteriormente socializado no Encontro Internacional do Projeto MUS-E. Muitas vezes, nos momentos iniciais das aulas, formávamos um círculo onde era possível trabalhar com diferentes materialidades, com o intuito de concentrá-los e integrá-los enquanto grupo, focados em um mesmo objetivo. A exemplo da utilização de um tecido, que era lançado alternadamente para os colegas, juntamente com a pronúncia de seus nomes, era possível perceber, nos sorrisos das crianças, o encantamento pelo momento lúdico de liberdade e 
relação com os colegas. Muitas vezes, os corpos acompanhavam também, desordenados, o lançamento do tecido para o chão, como que querendo driblar a regra do jogo e instaurar um pequeno caos - momentos raros no contexto escolar, que os mantém em carteiras praticamente do início ao final do período.

Em uma dessas aulas na sala destinada às práticas artísticas, ao ser inserido em um processo criativo que estava sendo desenvolvido, $\mathrm{M}^{5}$. recebeu a função de acompanhar o personagem do rei, mas sempre que tentava se aproximar do menino que representava a majestade, este era rejeitado e ofendido. Nessa circunstância, M. se descontrolava e começava a chorar, gritar e a correr pela sala - o que é perfeitamente compreensível. Como educadora que acompanhava o processo, era visível constatar que os alunos não se aproximavam do colega, nem permitiam que este o fizesse. A dificuldade nas relações não se restringia apenas a essas crianças, mas até mesmo na formação de um círculo de mãos dadas, muitos mudavam de lugar, negando-se a pegar na mão de um colega de turma. Com mediação constante nessas circunstâncias, as aulas de Expressão Dramática podem se converter num espaço profícuo para se trabalhar as relações interpessoais, a ética, o respeito e a empatia.

No que diz respeito às crianças com autismo, que frequentam a Unidade de Ensino Estruturado para a Educação de Alunos com Perturbações do Espectro do Autismo (PEA) na referida escola, elas nem sempre participam da rotina de sala de aula, conforme verificado nas aulas de Expressão Dramática. Essas aulas não são consideradas fundamentais para seu desenvolvimento, pois não há indicação precisa sobre a sua participação nelas. Entre os objetivos da Unidade estão: promover a participação dos alunos com autismo nas atividades curriculares, entrosando com os seus pares de turma. Observo que esta ação está diretamente relacionada a uma frequência desses alunos em sala de aula com mediação constante dos profissionais envolvidos para que, principalmente, sejam bem recebidos pelos seus pares.

\footnotetext{
${ }^{5}$ M. é um dos estudantes do $4^{\circ}$ ano da Escola Básica da Cruz da Picada, com diagnóstico de autismo e que frequenta a Unidade de Ensino Estruturado para a Educação de Alunos com Perturbações do Espectro do Autismo.
} 
No Brasil, o Transtorno do Espectro Autista (TEA) ${ }^{6}$ consiste na presença de um desenvolvimento comprometido, caracterizado por dificuldades significativas de interação social, e um repertório muitas vezes restrito de atividades e interesses; assim como pela presença de comportamentos atípicos e repetitivos. Há diferentes níveis de gravidade no que diz respeito a dificuldades de comunicação. São também mencionados, em alguns casos, comprometimentos ao nível da função cognitiva e/ou problemas de linguagem. Além disso, a criança com autismo que não consegue desenvolver a alteridade, nem a reciprocidade, não se vê implicada no meio dos outros.

Acreditamos que a convivência compartilhada da criança com autismo na escola, a partir da sua efetiva inclusão no sistema de ensino regular, com mediação adequada, oportunize novos contatos e favoreça não só o seu desenvolvimento, mas o das outras crianças, na medida em que estas últimas convivam e aprendam com as diferenças. Infelizmente esta não é uma realidade constante. Um estudo realizado por pesquisadoras portuguesas tentou compreender as opiniões dos docentes após o Decreto Lei 3/2008 (Portugal, 2008), visto este ter constituído uma ruptura com o anterior decreto, no que diz respeito ao papel ativo do educador e do professor do ensino regular.

Segundo Thomas e Loxley (2007), não ter estratégias de ensino adequadas a uma pedagogia inclusiva conduz os docentes a sustentarem a necessidade de unidades de apoio, não considerando benéfico que todos os alunos sejam incluídos nas salas de aula do ensino regular (VIEIRA-RODRIGUES; SANCHES-FERREIRA, 2017, p. 49).

Por outro lado, a investigação também revelou que havia quase uma unanimidade na defesa de que a presença dos alunos nas turmas é um benefício para o aluno com incapacidades, mas também para o desenvolvimento pessoal e social dos alunos com desenvolvimento típico.

\footnotetext{
${ }^{6}$ Aqui utilizo a expressão transtorno do espectro autista como é utilizada no Brasil e como aparece no DSM (Diagnostic and Statistical Manual of Mental Disorders), manual diagnóstico e estatístico elaborado pela Associação Americana de Psiquiatria. Entretanto, há críticas ao DSM que ressaltam o fato de o manual transformar o sofrimento psíquico em patologias de cunho cerebral.
} 
Em maio de 2019, quando acontecia o Encontro Internacional do Projeto MUS-E, outra criança com autismo participava do evento assistindo as apresentações na referida escola. O Encontro é um momento em que artistas e docentes de diferentes países conhecem as escolas envolvidas, os contextos e partilham práticas educativas e artísticas de significativo valor para a promoção do sucesso dos alunos envolvidos. Mesmo motivada e visivelmente interessada no processo, essa criança foi contrariadamente retirada da sala pela profissional da Unidade, pois estava no seu horário de almoço, o que não podia ser alterado na sua rotina.

No mesmo encontro, o Workshop oferecido por uma das artistas mobilizou adultos e crianças através de um exercício criativo com jornais e música. A partir da proposição de reagirem ao que a condutora do processo fazia com um jornal, amassando, rasgando em diferentes dimensões e velocidades o papel, os corpos deviam responder expressivamente, como se fossem o próprio objeto sentindo a interferência/agressão, alimentados ainda pela atmosfera da música. Era possível observar como crianças que habitualmente não se relacionavam com outras da mesma turma, misturadas aos adultos e vivenciando o jogo com essas materialidades mostravam-se mais espontâneas, próximas e afetivas.

Assim como nesses encontros, as aulas e as atividades de expressão artística são os raros momentos em que é oportunizado aos alunos saírem de suas carteiras e se relacionarem com os colegas. São essas "lacunas", bem como as aulas de educação física e a hora do recreio, que os permite serem crianças, possibilitando um movimento de socialização. 
Figura 2 - Recreio na área externa da Escola EB1 Cruz da Picada

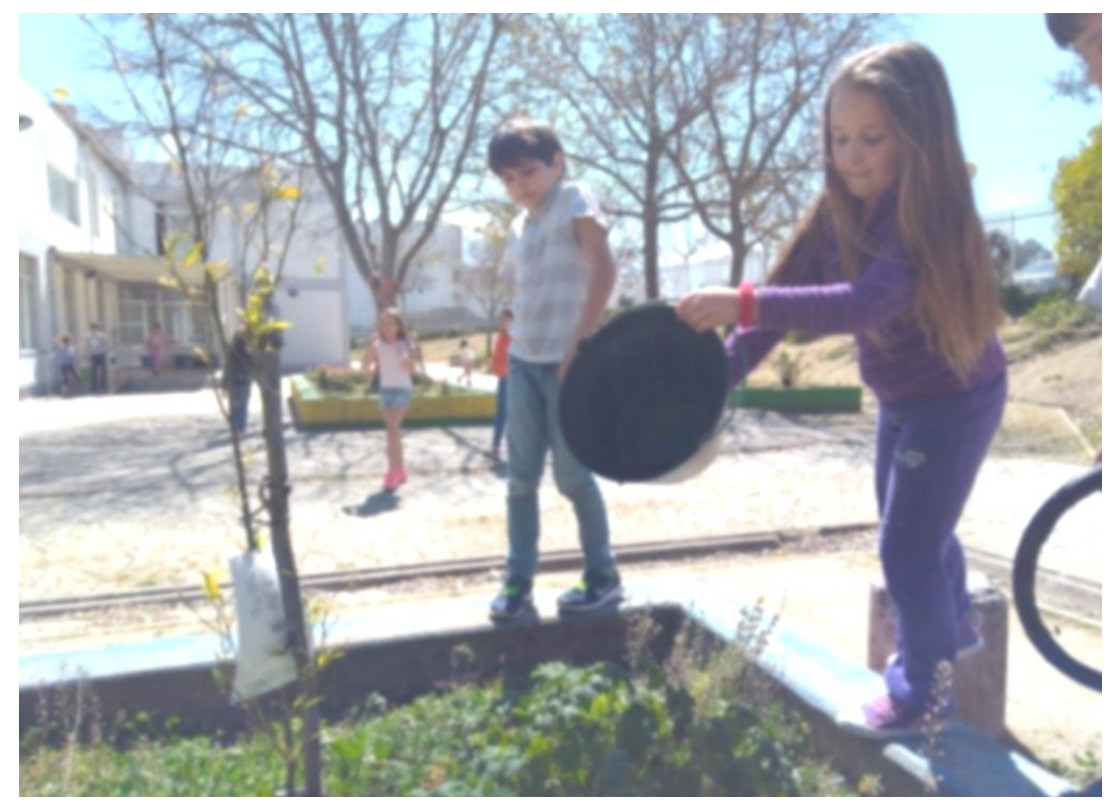

Fonte - Arquivo pessoal - abril de 2019

Na Escola da Cruz da Picada uma funcionária acompanha frequentemente os alunos no horário do recreio no espaço externo que conta com área verde. Em suas ações sensíveis de despertar o olhar das crianças para o espaço natural estão inclusas regar as pequenas mudas e plantas já crescidas sob sua orientação e colher frutos das árvores. Uma excelente oportunidade para trabalhar a interação dessas crianças com as da Unidade de Ensino Estruturado para a Educação de Alunos com PEA.

No que diz respeito a participação das crianças que frequentam a Unidade nas aulas de Expressão Dramática, dois aspectos são fundamentais: a mediação frequente e adequada e o "fazer parte do grupo", participar das aulas do início ao fim. É fundamental reiterar como é importante que as crianças tenham tempos e maneiras diferentes de estabelecer relações afetivas.

Muitos estudos comprovam que um processo comprometido de inclusão escolar e de interação social pode proporcionar a essas crianças oportunidades de convivência com outras da mesma faixa etária, constituindo-se num espaço de aprendizagem e de desenvolvimento de sua socialização. (CAMARGO; BOSA, 2009) 
Quando bem planejado, um trabalho pedagógico que vise a integração dessas crianças converte-se em um desafio com perspectivas, através de uma postura de confiança na capacidade de mudança do aluno. Alguns estudos (ADURENS; VIEIRA, 2018; VIEIRA-RODRIGUES; SANCHES-FERREIRA, 2017; FERNANDES; CHLESENER; MOSQUERA; TEIXEIRA, 2012; CAMARGO; BOSA, 2009) têm demonstrado que, quando isso ocorre e os professores estão adequadamente envolvidos no processo de inclusão, é possível verificar importantes ganhos para o desenvolvimento de crianças com autismo, quando incluídas no ensino comum. É possível também sugerir a partir dessas pesquisas que o comportamento dessas crianças pode ser influenciado considerando os contextos interativos, podendo se tornar mais leves com as intervenções precoces. Essas pesquisas também reforçam a importância da sensibilidade, perseverança e mediação adequada dos profissionais envolvidos no desenvolvimento de uma criança autista, facilitando as possibilidades de comunicação com o grupo, distanciando-a de um isolamento ainda maior.

Em pesquisa desenvolvida por Emellyne Lemos (2012), investigadora do Núcleo de Pesquisa em Interação Social e Desenvolvimento, foram realizadas observações no pátio de uma escola no horário do recreio, que comprovam a importância da mediação no processo de interação das crianças com autismo. Na situação relatada abaixo uma das crianças assume a função de mediadora para que a criança com autismo, que apenas observava demonstrando interesse no balanço e a gangorra, pudesse brincar:

Tal interesse pode ser analisado a partir de comportamentos de iniciativa dirigidos a esses objetos. Nesse sentido, a criança também demonstrou comportamentos de iniciativas dirigidas às ações de brincar em ambos os brinquedos. Entretanto, para brincar na gangorra, necessita-se de outra criança e, como pode ser observado, a criança autista, embora olhasse as pessoas, não demonstrava iniciativas dirigidas às mesmas, denotando a necessidade de mediação para tanto. Com pouca mediação da professora, a criança autista dedica parte do tempo no pátio brincando no balanço. Porém, ao dirigir-se à gangorra, uma das crianças percebe e realiza um convite sem mediação das professoras para brincar neste brinquedo. Nesse momento, ocorrem olhares (7) e demonstração de afeto (2) da 
criança com desenvolvimento típico dirigidos à criança com espectro autista. É interessante notar o respeito, a sensibilidade e a empatia demonstrados durante a referida brincadeira pela criança com desenvolvimento típico. Esta, ao observar os comportamentos não verbais da criança autista, inicia, dá continuidade e finaliza a brincadeira perguntando à criança autista após alguns minutos: "Quer parar?". Nesse momento, a criança autista a olha e desce da gangorra, dirigindo-se a outro brinquedo. (LEMOS, 2012, p.137, 138)

Em trabalho realizado no Brasil com crianças com autismo, a coautora Celida Salume verificou em trabalho psicopedagógico ${ }^{7}$ e artístico-pedagógico que, quando mediadas por um adulto, essas crianças se inserem mais facilmente nas brincadeiras, jogos e atividades em grupo, e tem a possibilidade de trabalhar ludicamente o potencial expressivo do seu corpo - o que é de fundamental importância para lançarem-se em oportunidades de aprendizagem e de socialização, trazendo resultados objetivos, avanços e maior facilidade para moverem-se nesse processo. À medida que essas crianças vão conhecendo e experienciando diferentes ambientes, suas expectativas relativamente a esses espaços, e aos seus acontecimentos, passam a ter a mediação da realidade e de encontros afetivos, que possibilitam terem segurança de ser, diminuir suas ansiedades e sair da dispersão o que geralmente ocorre em função do desconhecido, e de situações de rejeição, como as que são observadas em sala de aula, por falta de mediação adequada dos profissionais envolvidos.

$\mathrm{Na}$ ocasião em que Celida ministrava aulas de Teatro para alunos do ensino fundamental na Escola Sarapiquá em Florianopólis/SC, uma das turmas do $5^{\circ}$ Ano contava com uma criança com autismo que, inicialmente participava das aulas acompanhada por uma psicopedagoga. N. não fixava o olhar, praticamente não interagia com as outras crianças e ficava sentada durante as aulas fazendo atividades como recortar e colar, orientadas com o auxílio de sua acompanhante. Aos poucos, parte da mediação de sua participação nas aulas de Teatro foi transferida para as próprias crianças da turma, diminuindo sua dependência e

\footnotetext{
7 Trabalho psicopedagógico realizado em termos de articulação interdisciplinar com o Grupo Mediações de estudos de casos clínicos do NUCA (Núcleo Castor de Estudos e Atividades em Existencialismo) em Florianópolis SC.
} 
ampliando sua autonomia, o que possibilitou, mesmo com suas limitações em relação à fala, uma integração maior com os colegas. No Projeto Formas Vivas, N. construiu bonecos de manipulação direta, participou de atividades, exercícios e jogos teatrais e finalizou sua participação no processo criativo fazendo um mágico na apresentação final realizada em um teatro da cidade. O projeto didático tinha por objetivo proporcionar aos alunos uma vivência teatral com enfoque na expressão corporal e no teatro de bonecos, envolvendo diferentes linguagens artísticas e socializando o resultado do percurso criador na escola e/ou na comunidade. Entre o registro avaliativo solicitado pela professora do aproveitamento de $\mathrm{N}$. nas aulas de Teatro, e que foi apresentado pela psicopedagoga que o acompanhava, estavam as seguintes palavras:

[...] Se para os colegas do N..., sem as limitações que ele encontra devido ao autismo, já é um desafio o Teatro, para o N... o desafio foi maior. Mas com certeza esse desafio do diferente, do novo, de participar com os colegas, vem sendo vencido aos poucos. É claro que a interação do $\mathrm{N}$. com os seus colegas não depende somente dele, mas também dos colegas. Essa interação, esse envolvimento nas aulas de Teatro, depende também da disponibilidade, disposição e vontade de nos despir de nossos preconceitos. Nas atividades em grupo sei que muito foi difícil trabalhar com o N... Não porque queriam, mas porque não sabiam como agir. Mas isso, aos poucos, todos nós estamos aprendendo. Ter participado da apresentação final com certeza foi um desafio para o N.... Entrar naquele palco sozinho, sem ninguém pra segurar sua mão foi um desafio. Ele estava feliz e ultrapassou barreiras e desafios que somente ele conhece. (2005)

Nesse sentido, são as aulas de Teatro no Brasil ou de Expressão Dramática em Portugal que, no contexto da educação básica possibilitam que os alunos saiam de suas carteiras, mesmo que por um curto espaço de tempo, para se expressar, se relacionar com o grupo, serem ouvidos e desenvolver uma sensibilidade poético-estética através do fazer teatral.

No artigo Teatro na Escola Pública: Um direito! (2015), a coautora Celida Salume traz considerações no que diz respeito à presença ou à falta do ensino de Teatro nas escolas públicas brasileiras. Apesar da Lei de Diretrizes e Bases da 
Educação Nacional (LDB 9.394/96) garantir a inclusão da Arte no currículo das Escolas desde 1996, assim como o Projeto de Lei 7032/2010, uma série de fatores emperram a sua total efetivação. A Arte, assim como o Teatro precisa constantemente justificar-se e/ou defender-se no contexto educacional. A rotina e dificuldades enfrentadas nesses espaços acabam adormecendo o perfil do professor artista que muitas vezes abandona o corpo do estudante nesse processo, caindo na armadilha de aulas mais teóricas para manter o controle da turma. Em seu texto Preliminares: sobre Infância, Corpo, Educação e Teatro (2018) ela discute as relações entre corpo, educação e aprendizagem na infância. Ela faz lembrar que no Ensino Fundamental 1, no 1 Ciclo, o corpo da criança ainda é um corpo brincante, mas na maioria das vezes, a ludicidade só encontra o seu espaço na educação infantil. À perspectiva de ensino, em boa parte das escolas, interessa um corpo inerte, disciplinado, silencioso e pronto para receber o conhecimento; assim corpo e aprendizagem caminham em descompasso no espaço escolar.

\section{RESULTADOS PRELIMINARES: POSSIBILIDADES FUTURAS}

Em comum, as experiências citadas nesse texto voltam-se para a dimensão formativa do professor ou artista que trabalha Artes nas escolas. Acreditamos no impacto dessas práticas no sentido de possibilitar a humanização dos envolvidos. De forma geral, a linguagem da educação está repleta de certezas, de fórmulas provenientes das ciências positivistas e de saberes mensuráveis. Mas, como bem nos alerta Larrosa (2011, p. 26), "talvez nos falte uma língua para a experiência. Uma língua que esteja atravessada de paixão, de incerteza, de singularidade. Uma língua com sensibilidade, com corpo; atravessada de exterioridade, de alteridade".

No que diz respeito à inclusão dos alunos com autismo na escola regular podemos afirmar que, com a mediação dos educadores, as crianças que passam a ter contato com alunos que apresentam essas dificuldades, tendem a se conscientizar, ampliar o respeito pelo outro e pela diversidade, tornando-se indivíduos melhores. Em sintonia com uma das propostas fundamentais da obra 
educativa de Paulo Freire, faz parte de nossa função fazer emergir uma consciência crítica no nosso educando, que não é apenas criança ou adulto, mas, muitas vezes, oprimido e excluído. Nesse sentido, a educação nos torna sujeitos ativos, responsáveis, que acreditam no crescimento do indivíduo e nas mudanças possíveis a partir de um trabalho coletivo nas escolas.

Em função das situações ocorridas nas aulas de Expressão Dramática na Escola da Cruz da Picada, como a frequência alternada ou a chegada tardia dos alunos nesses encontros, o que não facilita a interação das crianças, foi pontuado em reunião avaliativa ao final do ano letivo, a necessidade da Unidade de Ensino Estruturado para a Educação de Alunos com Perturbações do Espectro do Autismo dialogar de forma mais articulada com a escola e contar com o apoio e parceria dos profissionais envolvidos para um acompanhamento mais adequado das crianças nas aulas.

O trabalho de pesquisa realizado com as materialidades e suas múltiplas possibilidades foi também compartilhado com professores/artistas de outros países em workshop ministrado no ERASMUS+ "ARTE POR LA CONVIVENCIA" MEETING IN PORTUGAL encontro internacional de artistas e docentes MUS-E, que teve lugar em Évora, em maio de 2019.

Figura 3 - Artistic training workshop for artists, teachers and students of U.E.

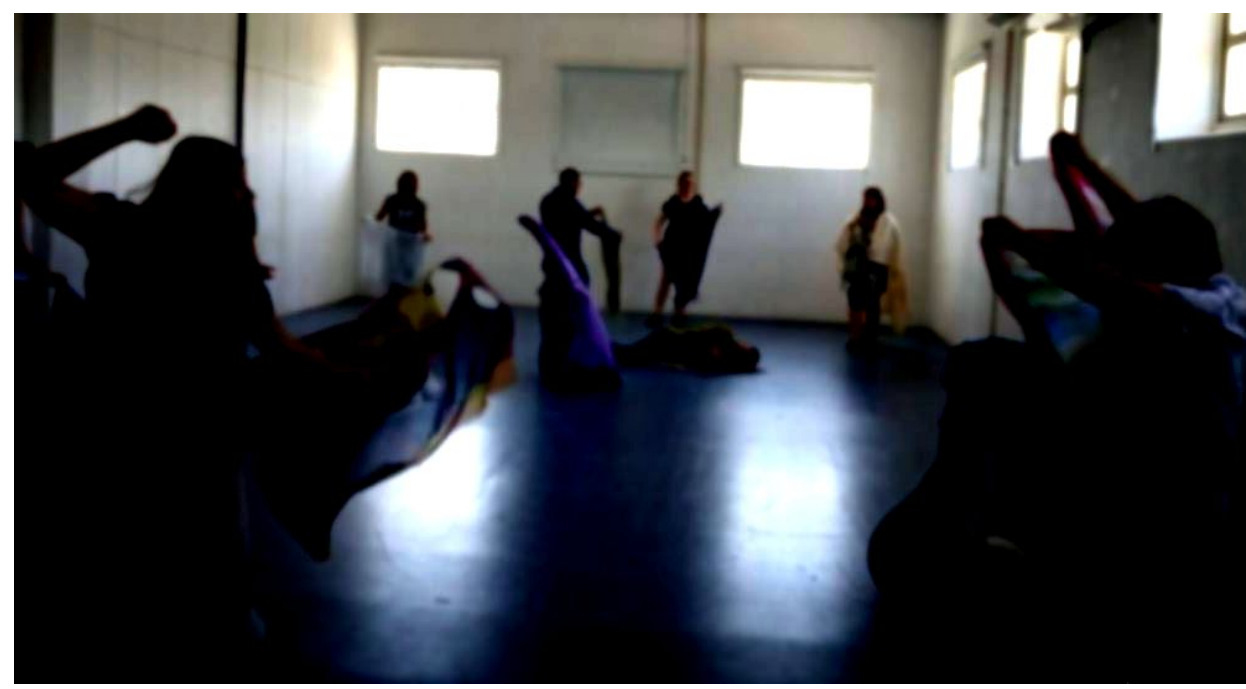

Fonte - Arquivo pessoal - Maio 2019 
Os aspectos mais significativos dessa investigação voltam-se para a importância do corpo no processo de aprendizagem, não apenas nas aulas de Expressão Dramática, mas mesmo em outras disciplinas. É o corpo em movimento que possibilita o contato entre os estudantes, uma aprendizagem mais significativa, na qual os alunos possam atribuir sentido ao que aprendem. Da mesma forma, a relação com o espaço - que muitas vezes é ignorado para além da sala de aula - e a importância do jogo nessas práticas. Os objetivos do jogo em Ryngaert vão de encontro a educação de um indivíduo ideal, aberto, disponível, com um olhar e uma atitude ampliados em relação ao mundo.

Através do projeto Estudo das narrativas e as dimensões simbólicas e políticas na construção do imaginário a partir da cidade, as pesquisadoras projetam para 2020/21 ações em conjunto que viabilizem a multiplicação de experiências teatrais no âmbito dos espaços institucionais (Universidade e Escolas) e da cidade, instaurando percursos artísticos envolvendo espaço público, memória, afeto, pertencimento e sustentabilidade, que sejam enriquecedores na formação de docentes e pesquisadores da pedagogia do teatro no contexto brasileiro e português construindo novas colaborações e possibilidades.

Aproximando-se do contexto educacional ambicionam trabalhar a cidade como sala de aula, como um lugar a ser apropriado pelo uso e interação criativa. As ações do projeto se propõem a colocar os corpos brincantes de estudantes da educação básica na rua, em contato orgânico com a cidade, promovendo o cruzamento interdisciplinar e o alargamento de fronteiras e territórios, trabalhando a noção de lugar como constructo da experiência criativa vivenciada.

\section{REFERÊNCIAS}

ADURENS, Fernanda D. L.; VIEIRA; Camila M. Concepção de professores sobre a inclusão do aluno com autismo: uma pesquisa bibliográfica. Cadernos de Pós-Graduação em Distúrbios do Desenvolvimento. São Paulo, v. 18, n. 2, p. 94-124, jul./dez. 2018. Disponível em: http://dx.doi.org/10.5935/cadernosdisturbios.v18n2p94-124 
BEZELGA, I. O Papel das Artes na Promoção do Sucesso Académico: O Prazer de Fazer Acontecer! Revista Portuguesa de Educação Artística (RPEA) v. 7 n. 1 (2017): RPEA, p.67-78. Disponível em: https://rpea.madeira.gov.pt/index.php/rpea/article/view/52/58

Revisitar os percursos da educação artística para enfrentar desafios: o caso do teatro-educação. Revista Digital do LAV - Santa Maria - vol. 8, n. 2, p. 18 - 47. mai./ago. 2015. ISSN 1983 - $7348 . \quad$ Disponível em: https://periodicos.ufsm.br/revislav/article/view/19863

CAMARGO, Síglia P. H.; BOSA, Clonice A. Competência social, inclusão escolar e autismo: revisão crítica da literatura. Psicologia \& Sociedade. vol.21 no.1 Florianópolis Jan./Apr. 2009. On-line version ISSN 1807-0310. Disponível em: https://doi.org/10.1590/S0102-71822009000100008

FERNANDES L.B; SCHLESENER, A., MOSQUERA C., TEIXEIRA R.M., Ensino de Arte e Autismo: um Relato de Extensão. Revista Educação, Artes e Inclusão, Florianópolis, v. 5, n. 1, s/n. 2012.

LARROSA, J. (org.) Elogio da escola. Tradução: Fernando Coelho - $1^{\text {a }}$ ed. Belo Horizonte: Autêntica Editora, 2017.

LARROSA, J. Experiência e alteridade em educação. Revista Reflexão e Ação, Santa Cruz do Sul, v.19, n2, p.04-27, jul./dez. 2011.

LEMOS, E. L. M. D. A. Inclusão de crianças autistas: um estudo sobre interações sociais no contexto escolar. Dissertação de Mestrado. Universidade Federal da Paraíba, João Pessoa, 2012.

LEVINAS, E. Entre nós: ensaios sobre a alteridade. Trad. Pergentino Stefano Pivatto (coord.). Petrópolis: Editora Vozes, 2005.

MENDONÇA, C.S. Preliminares: sobre Infância, Corpo, Educação e Teatro. Paisagens educativas do ensino de teatro na Bahia: saberes, experiências e formação de professores. Cilene N. Canda e Celida S. Mendonça (Org.), Edição: $1^{\text {a }}$ ed. Salvador, EDUFBA, 2018, p.267-286.

Teatro na Escola Pública: Um direito! Cadernos do GIPE-CIT: Grupo Interdisciplinar de Pesquisa e Extensão em Contemporaneidade, Imaginário e Teatralidade / Programa de Pós-Graduação em Artes Cênicas - Salvador (BA): UFBA/PPGAC, №35, 2015, p. 08-24. Disponível em: http://www.ppgac.tea.ufba.br/wp-content/uploads/2016/03/GIPE-CIT-N35-2015.pdf

"Sobre importâncias: saboreando materialidades no processo de criação cênica". In: Anais do IV Colóquio Internacional de Educação e Contemporaneidade, 2010, São Cristóvão - SE, 2010.

RYNGAERT, J.P. Jogar, representar: práticas dramáticas e formação. Tradução: Cássia Raquel da Silveira. São Paulo: Cosac Naify, 2009. 
SALLES, C.A. Gesto inacabado - processo de criação artística. São Paulo: Annablume, 1998.

2008

Redes da criação: construção da obra de arte. $2^{\mathrm{a}}$ ed. Vinhedo: Horizonte,

VIEIRA-RODRIGUES, M. de M.; SANCHES-FERREIRA, M. M. P. A inclusão de crianças com necessidades educativas especiais no ensino regular em Portugal: a opinião de educadores de infância e de professores do $1^{\circ}$ ciclo do ensino público e privado. Rev. Bras. Ed. Esp., Marília, v. 23, n. 1, p. 37-52. jan./mar. 2017. Disponível em: <http://www.scielo.br/pdf/rbee/v23n1/1413-6538-rbee-23-01-0037.pdf>. Acesso em: 22 fevereiro 2020. 